\title{
Sugar mimics from sugar lactones
}

\author{
George W. J. Fleet, Juan C. Estevez, Martin D. Smith, Yves Blériot, Carmen de la Fuente, \\ Thomas M. Krülle, Gurdyal S. Besra, Patrick J. Brennan, Robert J. Nash, Louise N. \\ Johnson, Nikos G. Oikonomakos and Willy Stalmans
}

Dyson Perrins Laboratory, Oxford Centre for Molecular Sciences, Oxford University, South Parks Road, Oxford OXI 3QY UK; Department of Microbiology, Colorado State University, Fort Collins, Colorado 80523 USA; Institute of Grassland and Environmental Research, Plas Gogerddan, Aberystwyth, Cardiganshire SY23 3EB UK; Afdeling Biochemie, Faculteit Geneeskunde, Katholieke Universiteit Leuven, Herestraat 49, B-3000 Leuven, Belgium; National Hellenic Research Foundation, 48, Vas, Constantinou Avenue, Athens 11635, Greece; Laboratory of Molecular Biophysics, Rex Richards Building, Parks Road, Oxford OXI 3QU UK.

\begin{abstract}
The potential of carbohydrate mimics which incorporate an $\alpha$-amino acid moiety at the anomeric position of the sugar is illustrated by the synthesis of both furanose and pyranose analogues of L-rhamnose in a study related to inhibition of the biosynthesis of mycobacterial cell walls. Some amino acid analogues of glucopyranose are inhibitors of glycogen phosphorylase ard may provide an approach to the treatment of late-onset diabetes; bicyclic lactone intermediates provide relatively easy access to both oper chain and spiro derivatives of glucose in which both nitrogen and carbonyl functions are present at the anomeric position, and in which the anomeric configuration is defined. Other glucose analogues were found to be inhibitors of glucokinase and glucose-6-phosphatase; such materials may allow the investigation of metabolic control by the levels of sugar phosphates.
\end{abstract}

\section{Introduction}

Nature has invested much time in devising enzymes and receptors which are highly specific in their interactions with carbohydrates; in many cases, little is known about the protein structure which interacts with the specific sugar. Compounds that contain a carbohydrate recognition site [to provide the binding] together with an opportunity for the synthesis of diverse structures [to provide specificity] could produce leads for the control of individual steps of carbohydrate metabolism. Ideally, the mimic should retain as many of the functional groups in the parent sugar as possible and, in particular, retain the stereochemistry at all the chiral centres of the carbohydrate. Structures that incorporate a nitrogen function as well as a carboxyl group at the anomeric position are remarkably stable, so that there are four isomers for each carbohydrate - with $\alpha$ and $\beta$-nitrogen substituents in both furanose and pyranose forms. ${ }^{1}$ Such derivatives would allow the sugar epitope to be kept while a wide range of structural moieties could be introduced by amide bond formation. This paper illustrates the preparation of such analogues of L-rhamnose and D-glucose, as well as other mimics of glucose which are derived from substitution of a prochiral proton in the hydroxymethyl group by carbon substituents.

\section{Mimics of L-Rhamnose}

Carbohydrates in the cell wall of mycobacteria present perfect targets for both the study of the biosynthesis of the cell wall and possible new strategies for the treatment of tuberculosis. $\alpha$-D-Galactofuranose, Darabinofuranose and L-rhamnose are all important components of mycobacterial cell walls and none of these sugars have any role in mammalian metabolism; thus, compounds which interfere specifically with the biosynthesis of any of these fragments, or their incorporation into cell walls, or subsequent modification of the cell wall structure, should not have any deleterious effect on humans. ${ }^{2}$<smiles>C[C@@H]1O[C@H](O)[C@@H](O)[C@H](O)[C@H]1O</smiles>

1<smiles>C[C@@H](O)[C@H]1O[C@H](O)[C@@H](O)[C@H]1O</smiles>

2<smiles>CNC1(O)O[C@H](C)[C@@H](O)[C@@H](O)[C@H]1O</smiles>

3<smiles>CNC1(O)O[C@H]([C@H](C)O)[C@@H](O)[C@@H]1O</smiles>

4

L-Rhamnose 1 is a constituent of a key disaccharide linker in the mycobacterial cell wall; compounds which inhibit either the biosynthesis of L-rhamnose or its incorporation into the cell wall might present a new approach to the study of such systems. It is not clear whether mimics of the pyranose 1 or furanose 2 would 
provide the better initial search for inhibitors of either step; among other rhamnose mimics, we have devised a series of intermediates for the synthesis of mimics such as 3 and $\mathbf{4}$ in which the anomeric positions of the pyranose and furanose forms have an $\alpha$-amino acid fragments. All such analogues require the introduction of an extra carbon to L-rhamnose at the oxidation level of an acid, together with introduction of nitrogen; the azidolactone $\mathbf{7}$ and the azidoester $\mathbf{8}$ are the starting materials for the generation of the pyranose $\mathbf{3}$ and furanose 4 analogues, respectively [Scheme 1]. Thus initial protection of rhamnose 1 as the acetonide followed by the Kiliani ascension ${ }^{3}$ gave the $\delta$-lactone 5 as the major product. Reaction of the diol 5 with triflic anhydride caused regioselective esterification to give the monotriflate 6 which underwent subsequent nucleophilic displacement with azide with overall retention of configuration to give the required azide 7 . Treatment of the triflate 6 in methanol with potassium carbonate induced ring opening by methoxide, followed by intramolecular displacement of the triflate with inversion of configuration to afford the tetrahydrofuran 10. Radical bromination gave a single bromide 9 which with sodium azide underwent nucleophilic displacement with inversion to give the azidoester $8{ }^{4}$

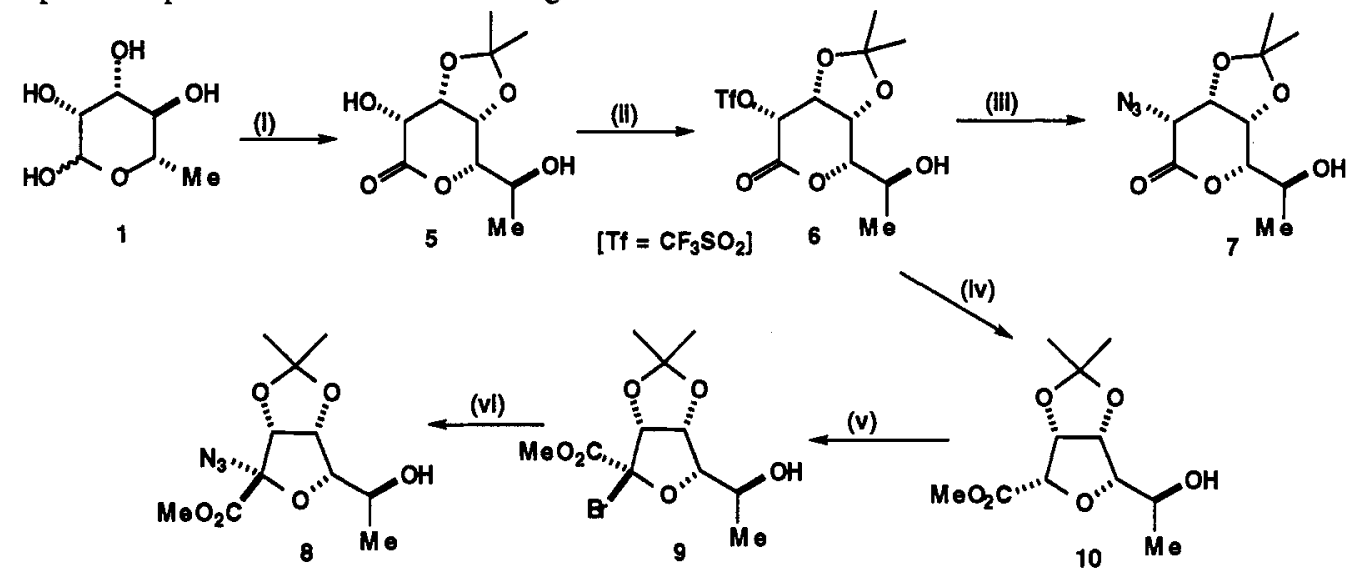

Scheme 1: (i) $\mathrm{Me}_{2} \mathrm{CO}, \mathrm{H}^{+}$; then $\mathrm{NaCN}$ (ii) $\mathrm{Tf}_{2} \mathrm{O}$, pyridine, $\mathrm{CH}_{2} \mathrm{Cl}_{2}$ (iii) $\mathrm{NaN}_{3}, \mathrm{DMF}$ (iv) $\mathrm{K}_{2} \mathrm{CO}_{3}, \mathrm{MeOH}$

(v) $\mathrm{N}$-bromosuccinimide, $(\mathrm{PhCOO})_{2}, \mathrm{CCl}_{4}$

The use of the azidolactone 7 to make pyranose analogues of rhamnose 3 is illustrated in the syntheses of the tripeptide 13 and the spirodiketopiperazine 14 [Scheme 2]. Hydrogenation of the azide 7 gave the aminolactone 11 which was coupled with protected glycine to give 12. Ionic bromination of 12 with $\mathrm{N}$-bromosuccinimide in acetonitrile in the presence of sodium acetate caused initial oxidation to give an intermediate acylated imine which spontaneously cyclised to form a bicyclic lactone 16, containing the rhamnopyranose moiety. ${ }^{5}$. The lactone 16 undergoes nucleophilic ring opening with amines. Thus, reaction of 16 with glycine methyl ester gave 17; subsequent hydrolysis of the acetonide afforded the tripeptide 13 . Hydrogenation of $\mathbf{1 6}$ in the presence of a palladium catalyst removed the Z-group to provide an intermediate amine which gave the spiro compound 15 spontaneously. Deprotection of $\mathbf{1 5}$ by aqueous trifluoroacetic acid gave the spirocyclic peptide 14.<smiles>CC(=O)C(O)[C@H]1OC(=O)[C@H](N)[C@H]2OC(C)(C)O[C@H]12</smiles>

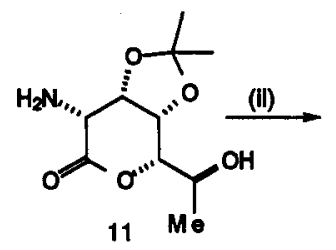

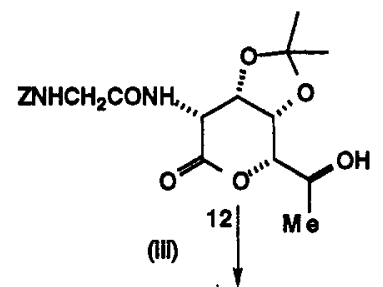<smiles>NC(=O)CNC[C@]1(O)O[C@H](O)C(O)[C@@H](O)[C@H]1O</smiles>

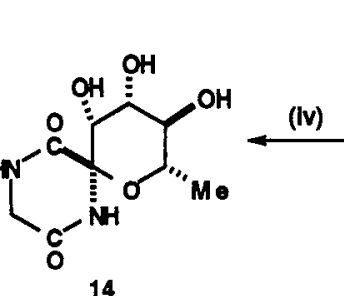<smiles>C[C@@H]1O[C@]2(CNCC(=O)N2)[C@H]2OC(C)(C)O[C@H]2[C@@H]1O</smiles>
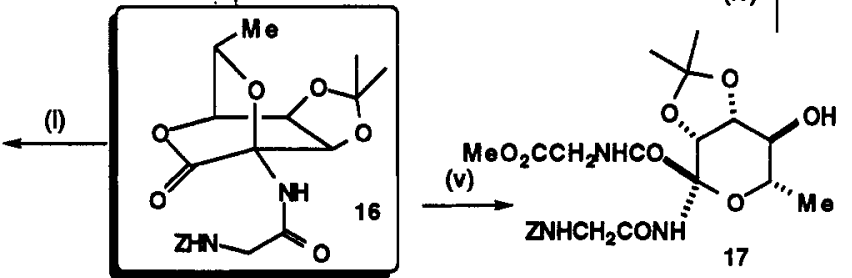

Scheme 2: (i) $\mathrm{H}_{2}, \mathrm{Pd}, \mathrm{EtOH}$ (ii) ZglyOH, ClCOOEt, $\mathrm{Et}_{3} \mathrm{~N}, \mathrm{THF}, \mathrm{MeCN}$ (iii) $N$-bromosuccinimide, NaOAc, MeCN (iv) $50 \%$ aq. $\mathrm{CF}_{3} \mathrm{COOH}$ (v) $\mathrm{MeO}_{2} \mathrm{C} \cdot \mathrm{CH}_{2} \cdot \mathrm{NH}_{3}{ }^{+} \mathrm{Cl}, \mathrm{NaOAc}, \mathrm{DMF}$ 


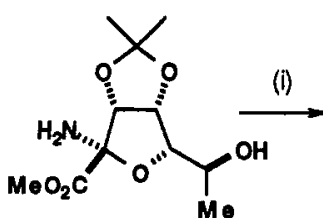

18

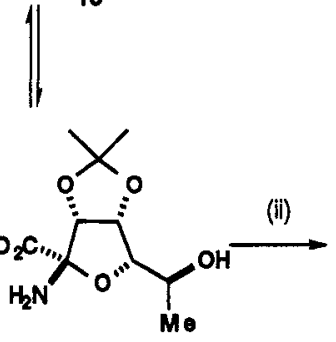

22

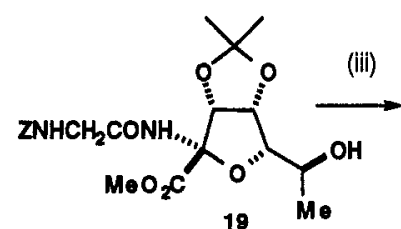

19

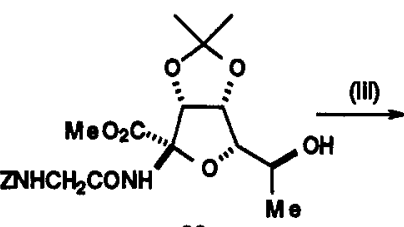

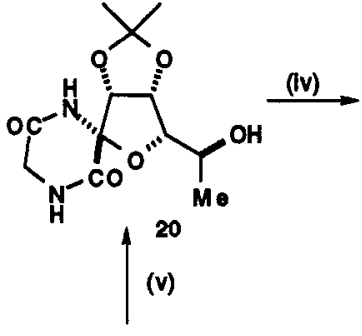<smiles>C[C@@H](O)[C@H]1O[C@]2(CNC(=O)N2)[C@H](O)[C@H](O)[C@H]1O</smiles>

21

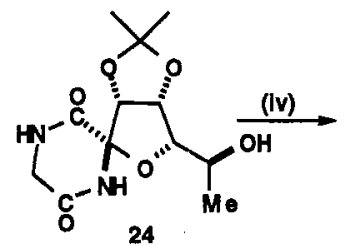<smiles>C[C@@H](O)[C@H]1O[C@@]2(CNCCO2)[C@H](O)[C@H]1O</smiles>

Scheme 3: (i) ZglyOH, ClCOOEt, $\mathrm{Et}_{3} \mathrm{~N}$, THF, MeCN (ii) ZGlyOH, DCC, 1-hydroxybenzotriazole, DMF

(iii) $\mathrm{H}_{2}$, Pd black, EtOH (iv) $50 \%$ aq. $\mathrm{CF}_{3} \mathrm{COOH}$ (v) tert-BuOK, DMF

The synthesis of $\mathbf{2 1}$ and 22 as mimics of rhamnoturanose 4 from the azidoester $\mathbf{8}$ is shown in Scheme $3 .{ }^{6}$ Hydrogenation of the azide 8 in the presence of palladium initially gives the corresponding amine 18. While $\mathrm{N}$-acylated compounds in both the pyranose and furanose systems are quite stable and do not mutarotate, the amine 18 is in slow equilibriurn with the anomer 22 . The amine 18 in which the amine is cis to the diol function is more stable than 22 and predominates in a ratio of approximately $4: 1$. Acylation of $\mathbf{1 8}$ with Z-glycine activated as a mixed anhydride gave predominantly 19; however, when the amine is coupled with Z-glycine activated with DCC and 1-hydroxybenzotriazole, the major product is 23 . Presumably in the first case, the more stable but more hindered and less nucleophilic amine 18 reacts with the mixed anhydride whereas in the case of the less reactive acylating agent generated by the second method, the less hindered amine 22 is responsible for the formation of the major product. Hydrogenation of $\mathbf{1 9}$ gives an amine which spontaneous cyclises onto the unhindered carbonyl group of the ester to give 20. In contrast, hydrogenation of $\mathbf{2 3}$ gave an aminoester which can be isolated and closes more slowly by attack on the more hindered ester to afford 24. The less stable 24 may be isomerised to 20 by treatment with base. There is no evidence of any isomerisation of the furanose derivatives 20 or 24 to give the pyranose analogue 15. Deprotection of 20 and 24 by acid hydrolysis allows access to 21 and 25 , respectively.

Thus, the above chemistry allows the synthesis of intermediates which are fairly easy to access and are capable of being introduced into diverse libraries of rhamnofuranose and rhamnopyranose mimics. These materials and other mimics of L-rhamnose ${ }^{7}$ are being studied in regard to their effects on mycobacterial cell wall biosynthesis and these results will be reported elsewhere.

\section{Mimics of D-Glucose}<smiles>O=C1NC(=O)[C@]2(N1)O[C@H](CO)[C@@H](O)C(O)[C@@H]2O</smiles><smiles>O=C1NC[C@@]2(N1)O[C@H](CO)[C@@H](O)C(O)[C@H]2O</smiles><smiles>[2H]C(=O)N[C@@]1(C(N)=O)OC(CO)[C@H](O)[C@H](O)[C@H]1O</smiles><smiles>O=C(P)N[C@@]12O[C@@H]([C@H](C(=O)O)OC1=O)[C@H](O)[C@H]2O</smiles>

Inhibition of glycogen phosphorylase (GP) may provide a new chemotherapeutic strategy for the treatment of late onset diabetes; ${ }^{2}$ as part of a long term study on the synthesis of analogues of glucopyranose, molecular modelling of inhibitors bound to the active site of GP predicted that the glucopyranose hydantoin 26 would be a very potent inhibitor of GP whereas the epimeric spirohydantoin $\mathbf{2 7}$ should not bind as well. Both these predictions were found to be true and $\mathbf{2 6}$ is the most powerful inhibitor of GP which binds at the catalytic site with $\mathrm{K}_{\mathrm{i}} 3 \mu \mathrm{M}$ whereas 27 is amuch weaker inhibitor with $\mathrm{K}_{\mathrm{i}} 320 \mu \mathrm{M}$. The first synthesis of the spirohydantoin was lengthy and not suitable for the synthesis of anything other than very small amounts of material; additionally, there was no control over the stereochemistry of the anomeric nitrogen. ${ }^{9}$ It was therefore desirable to have a synthesis of $\mathbf{2 6}$ which was more efficient, controlled the stereochemistry at the anomeric position, and would also allow a series of analogues of $\mathbf{2 6}$ to be prepared - both of an open chain 28 and spirocyclic nature. Such materials are relatively easily accessible via a series of acylated bicyclic lactones $\mathbf{2 9}$ in which the formation of the pyranose ring and the anomeric configuration is already established. 


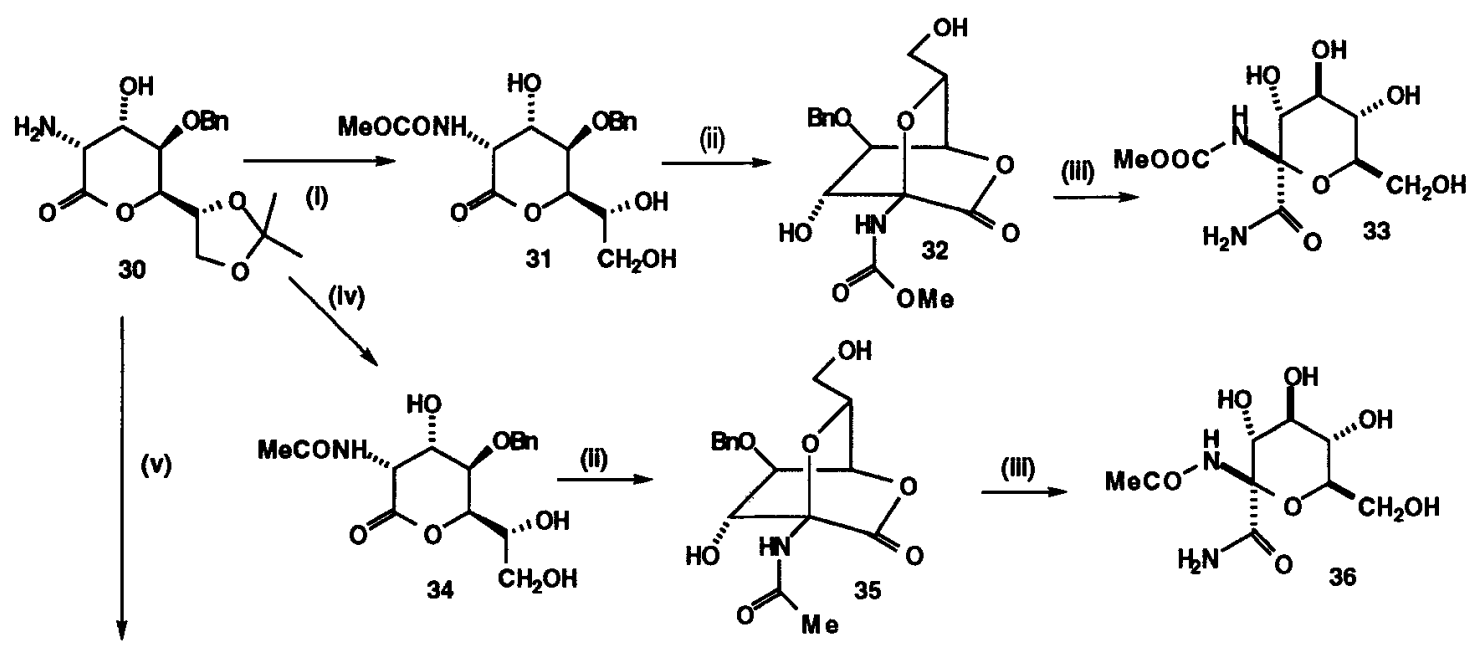

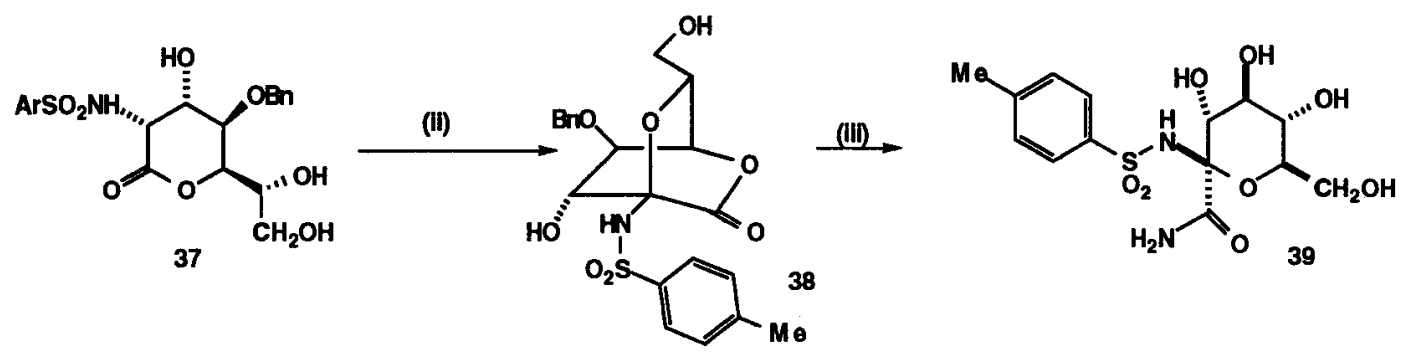

Scheme 4: (i) $\mathrm{ClCO}_{2} \mathrm{Me}$, pyridine; then $\mathrm{AcOH}, \mathrm{H}_{2} \mathrm{O}$ (ii) $\mathrm{N}$-bromosuccinimide, $\mathrm{NaOAc}, \mathrm{MeCN}$ (iii) $\mathrm{NH}_{3}$, then $\mathrm{H}_{2}, \mathrm{Pd}$ (iv) $\mathrm{Ac}_{2} \mathrm{O}$, pyridine: then $\mathrm{AcOH}, \mathrm{H}_{2} \mathrm{O}$ (v) TsCl, pyridine; then $\mathrm{AcOH}, \mathrm{H}_{2} \mathrm{O}$

The acetonide $\mathbf{3 0}$ is the starting material for all the bicyclic lactones 29 [Scheme 4]. ${ }^{10}$ Thus, reaction of 30 with methyl chloroformate in pyridine gave the carbamate 31. Removal of the acetonide by mild acid hydrolysis and subsequent oxidation with $\mathrm{N}$-bromosuccinimide yielded the bicyclic lactone 32 . The carbamate 32 may be opened by nucleophilic attack by a range of nucleophiles. For example, reaction with ammonia in methanol, followed by removal of the benzyl protecting group by hydrogenolysis afforded the amidocarbamate $33 ; 33$ is an open chain equivalent of 26 and is itself a good inhibitor of GP with $K_{i} 15$ $\mu \mathrm{M}$. Acetylation of the amine $\mathbf{3 0}$ and subsequent hydrolysis gave the amide 34 which on oxidation gave $\mathbf{3 5}$, easily elaborated to $\mathbf{3 6}$. Similarly tosylation of $\mathbf{3 0}$ and hydrolysis formed $\mathbf{3 7}$ which again can be oxidised by NBS to the bicyclic sulphonamide $\mathbf{3 8}$. Ring opening of $\mathbf{3 8}$ with ammonia and removal of the benzyl group afforded the open chain sulphonamide 39.

In all of the above cases, the stereochemistry at the anomeric position of the products is fixed by the rigid structure of the bicyclic lactones 29; there is no evidence of equilibration at the anomeric positions, so that these compounds are all kinetically stable for long periods in protic solvents.

The bicyclic carbamate 32 may also be used for the synthesis of 26 [Scheme 5]. Reaction of 32 with ammonia gave the ring opened amide 33. Treatment of 33 with potassium tert-butoxide in dimethylformamide induces cyclisation to a spirohydantoin from which the benzyl group may be removed by hydrogenolysis to give the potent GP inhibitor 26; there is no trace of the epimer 27 under these conditions. Treatment of 32 with hydrazine formed the open chain hydrazide $\mathbf{4 0}$ which spontaneously cyclised to the $\mathrm{N}$ aminohydantoin $\mathbf{4 1}$. Nitrosation of $\mathbf{4 1}$ caused very efficient deamination and this route is an easier synthesis of 26. Alternatively acetylation of $\mathbf{4 1}$ with acetic anhydride in pyridine followed by deprotection gave 42; thus 41 would allow the generation of a library of aminohydantoins by standard acylation techniques. Hydroxylamine reacted with the bicyclic lactone 32 to give initially the non-isolable hydroxamic acid $\mathbf{4 3}$ which formed the $\mathrm{N}$-hydroxyhydantoin 44 which on hydrogenolysis gave 45.

Although the value of these materials has been demonstrated in exploring structure-activity relationships in the inhibition of GP. ${ }^{11}$ There are many enzymes which handle glucose; it may be that there are other applications of the libraries that may easily be generated from these glucopyranose mimics in other metabolic process involving glucose. 


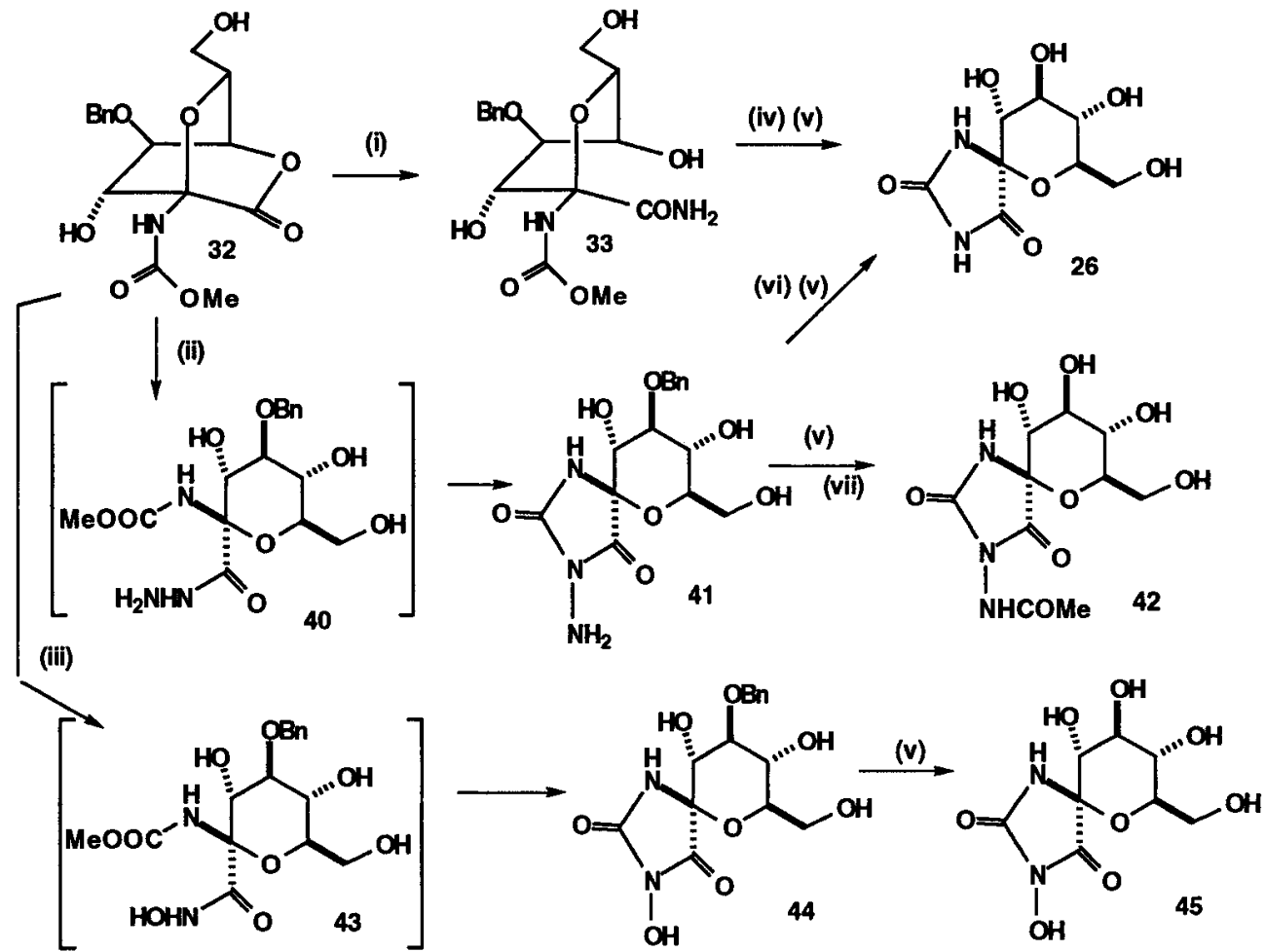

Scheme 5: (i) $\mathrm{NH}_{3}, \mathrm{THF}$ (ii) $\mathrm{NH}_{2} \mathrm{NH}_{2} \cdot \mathrm{H}_{2} \mathrm{O}$, THF (iii) $\mathrm{NH}_{3}, \mathrm{CH}_{2} \mathrm{Cl}_{2}$ (iv) tert-BuOK, DMF (v) $\mathrm{H}_{2}, \mathrm{Pd}, \mathrm{MeOH}$

(vi) amyl nitrite, $\mathrm{H}^{+}$(vii) $\mathrm{Ac}_{2} \mathrm{O}$, pyridine; then $\mathrm{NaOMe}, \mathrm{MeOH}$

There have been no reports of the biological properties of sugar analogues derived by adding a carbon substituent at C-6 of a sugar. Substitution of one of the prochiral hydrogens in the hydroxymethyl group of glucopyranose 46 by a methyl group would give rise to homo-L-fucose 47 and homo-D-altrose 48 , whereas substitution by a phenyl group would give the L- 49 and D- 50 diastereomers. Preliminary modelling studies indicated that there was room for accommodation of a methyl group in the catalytic site of GP and accordingly the analogues 47 and 48 were synthesised from D-glucuronolactone 51.<smiles>OC[C@H]1O[C@H](O)[C@@H](O)[C@H](O)[C@H]1O</smiles><smiles>O=[N+]([O-])C(O)C1O[C@H](O)[C@@H](O)C(O)[C@H]1O</smiles><smiles>OC(O)C1O[C@H](O)[C@@H](O)C(O)[C@H]1O</smiles><smiles>OC(c1ccccc1)C1O[C@H](O)[C@@H](O)C(O)[C@H]1O</smiles><smiles>O[C@@H](c1ccccc1)C1O[C@H](O)[C@@H](O)[C@@H](O)[C@H]1O</smiles>

Protection of 51 by acetonation to give 52 and subsequent silylation gave the fully protected lactone 53 which with methyl lithium gave the lactols 54. Reduction of 54 with sodium borohydride in ethanol caused a highly diastereoselective reduction with an accompanying migration of the silyl protecting group to afford 55 which on acid hydrolysis gave the homofucose analogue 47 [Scheme 6]. ${ }^{12}$

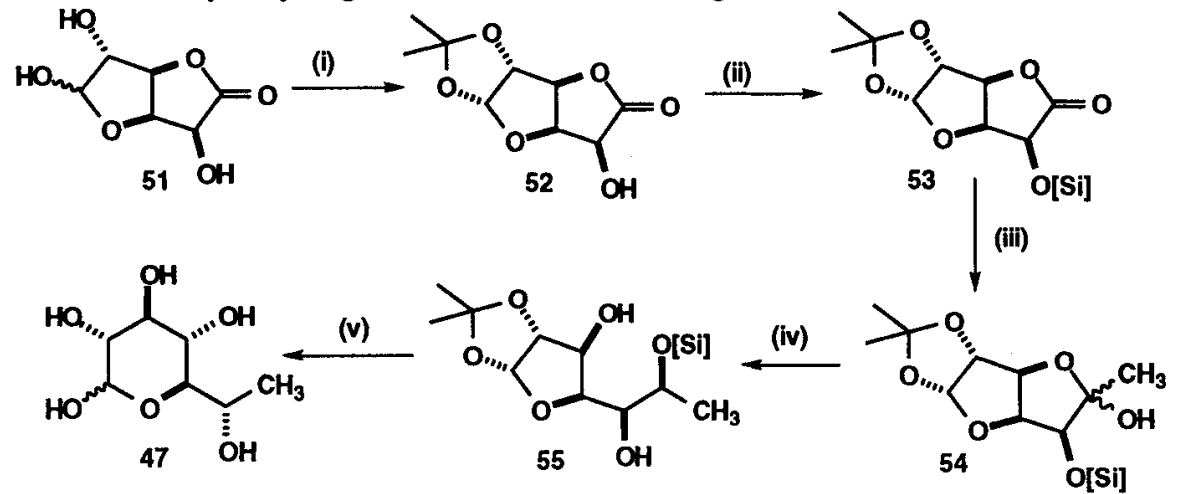

Scheme 6: (i) Acetone/ $\mathrm{H}^{+}$(ii) Me 2 tert-BuSiCl, DMF (ii) MeLi, THF (iv) $\mathrm{NaBH}_{4}, \mathrm{EtOH}$ (v) $\mathrm{H}_{2} \mathrm{O} / \mathrm{H}^{+}$ 
If the silyl group is removed from the lactol $\mathbf{5 4}$, sodium borohydride reduction is then unselective and thus allows the synthesis of $\mathbf{4 8}$ together with $\mathbf{4 7}$. Very similar chemistry occurs in the reaction of the lactol 54 with phenyl lithium, permitting easy access to the diastereomeric phenyl compounds 49 and 50 .

None of the compounds 47 - 50 caused any inhibition of GP; however it was found that, while the L-heptose 47 caused inactivation of glycogen synthase, the D-heptose $\mathbf{4 8}$ induced activation of glycogen synthase. Further study revealed that $\mathbf{4 7}$ inhibits glucokinase, while $\mathbf{4 8}$ is the first described inhibitor of glucose-6-phosphatase, causing intracellular levels of glucose-6-phosphate to rise. Inhibition of glucose-6phosphatase and/or activation of glycogen synthase may also provide novel additional strategies for the treatment of late-onset diabetes. The phenyl glucose 49 was a powerful inhibitor of glucokinase, while the epimeric phenyl compound $\mathbf{5 0}$ caused the same level of inhibition of glucokinase as that of the L-methyl analogue 47. ${ }^{13}$ It is surprising that there has been no prior investigation of analogues of sugars which arise from carbon substitution of the prochiral hydrogens of C-6 of hexoses. These preliminary findings indicate that such compounds may be useful in probing quite a wide variety of metabolic processes involving carbohydrates.

\section{Summary}

The range of biological assays - together with the enormous potential of small molecule analogues of individual carbohydrates generated by combinatorial techniques - should presage a new era of easily accessible materials which should allow a greater understanding of the ways in which carbohydrates bind to the enzymes and receptors that determine a very large number of biochemical processes. With a bit of luck, some of them might even suggest leads to compounds of chemotherapeutic value.

\section{References}

${ }^{1}$ J. W. Burton, J. C. Son, A. J. Fairbanks, S. S. Choi, H. Taylor, D. J. Watkin, B. Winchester and G. W. J. Fleet, Tetrahedron Lett., 1993, 34, 6119; J. C. Estevez, R. J. Estevez, H. Ardron, M. R. Wormald, D. Brown and G. W. J. Fleet, Tetrahedron Lett., 1994, 35, 8885; J. C. Estevez, H. Ardron, M. R. Wormald, D. Brown and G. W. J. Fleet, Tetrahedron Lett., 1994, 35, 8889; J. C. Estevez, D. D. Long, M. R. Wormald, R. A. Dwek, G. W. J. Fleet, Tetrahedron Lett., 1995, $36,8287$. ${ }^{2}$ G. S. Besra and D. Chatterjee, Tuberculosis, (Ed. Bloom, B. R), p.285, ASM Press, Washington DC, 1994.

${ }^{3}$ J. R. Wheatley, A. R. Beacham, P. M. de Q. Lilley, D. J. Watkin and G. W. J. Fleet, Tetrahedron Asymm., 1994, 5, 2523.

${ }^{4}$ J. C. Estevez, J. Saunders, G. S. Besra, P. J. Brennan, R. J. Nash and G. W. J. Fleet, Tetrahedron Asymm., 1996, 7, 383.

${ }^{5}$ J. C. Estevez, M. D. Smith, M. R. Wormald, G. S. Besra, P. J. Brennan, R. J. Nash and G. W. J. Fleet, Tetrahedron Asymm., 1996, 7, 391.

${ }^{6}$ J. C. Estevez, M. D. Smith, A. L. Lane, S. Crook, D. J. Watkin, G. S. Besra, P. J. Brennan, R. J. Nash and G. W. J. Fleet, Tetrahedron Asymm., 1996, 7, 387.

${ }^{7}$ A. A. Bell, L. Pickering, A. A. Watson, R. J. Nash, R. C. Griffiths, M. G. Jones and G. W. J. Fleet, Tetrahedron Lett., 1996, 37, in press; B. Davis, A. A. Bell, R. J. Nash, A. A. Watson, R. C. Griffiths, M. G. Jones, C. Smith and G. W. J. Fleet, Tetrahedron Lett., 1996, 37, in press; J. P. Shilvock, J. R. Wheatley, B. Davis, R. J. Nash, R. C. Griffiths, M. G. Jones, M. Muller, S. Crook, D. J. Watkin, C. Smith, G. S. Besra, P. J. Brennan and G. W. J. Fleet, Tetrahedron Lett., 1996, 37, in press.

${ }^{8}$ K. A. Watson, E. P. Mitchell, L. N. Johnson, J. C. Son, C. J. F. Bichard, M. G. Orchard, G. W. J. Fleet, N. G. Oikonomakos, D. D. Leonidas, M. Kontou and A. Papageoriouo, Biochemistry, 1994, 33, 5745; K. A. Watson, E. P. Mitchell, L. N. Johnson, J. C. Son, C. J. F. Bichard, G. W. J. Fleet, N. G. Oikonomakos, M. Kontou and S. E. Zographos, Acta Cryst. Sect. D, 1995, 51, 458; M. Board, M. Bollen, W Stalmans, Y. Kim, G. W. J. Fleet and L. N. Johnson, Biochem. J., 1995, 311, 845; N. G. Oikonomakos, M. Kontou, S. E. Zographos, K. A. Watson, L. N. Johnson, C. J. F. Bichard, G. W. J. Fleet and K. R. Acharya, Protein Sci., 1995, 4, 2469.

${ }^{9}$ C. J. F. Bichard, E. P. Mitchell, M. R. Wormald, K. A. Watson, L. N. Johnson, S. E. Zographos, D. D. Koutra, N. G. Oikonomakos, and G. W. J. Fleet, Tetrahedron Lett., 1995, 36, 2145.

${ }^{10}$ T. W. Brandstetter, C. de la Fuente, Y. Kim, R. I. Cooper, D. J. Watkin, N. G. Oikonomakos, L. N. Johnson and G. W. J. Fleet, Tetrahedron, 1996, 52, 10711; T. W. Brandstetter, C. de la Fuente, Y. Kim, L. N. Johnson, S. Crook, P. M. De Q. Lilley, D. J. Watkin, K. E. Tsitsanou, S. E. Zographos, E. D. Chrysina, N. G. Oikonomakos and G. W. J. Fleet, Tetrahedron, 1996, 52, 10721.

${ }^{11}$ T. M., Krülle, K. A. Watson, M. Gregoriou, L. N. Johnson, S. Crook, D. J. Watkin, R. C. Griffiths, R. J. Nash, K. E. Tsitsanou, S. E. Zographos, N. G. Oikonomakosand G. W. J. Fleet, Tetrahedron Lett., 1995, 36, 8291.

${ }^{12}$ Y. Blériot, K. H. Smelt, J. Cadefau, M. Bollen, W. Stalmans, K. Biggadike, L. N. Johnson, N. G. Oikonomakos, A. L. Lane, S. Crook, D. J. Watkin and G. W. J. Fleet, Tetrahedron Lett., 1996, 37, 7155.

${ }^{13}$ Y. Blériot, C. Veighey, K. H. Smelt, J. Cadefau, W. Stalmans, K. Biggadike, A. L. Lane, M. Muller, D. J. Watkin and G. W. J. Fleet, Tetrahedron Asymm., 1996, 7, 2761. 